\title{
Canadian Impact in Engineering, Science and Technology Diffusion to Africa
}

\author{
George S. Agoki, Engineering and Computer Science Department; Thomas Chittick, Department of \\ Agriculture; Andrews University, US 31, Berrien Springs, MI 49104-0370, U.S.A. agoki@andrews.edu
}

\begin{abstract}
The objective of this paper is to assess the major Canadian impact in the diffusion of engineering, science, and technology to Africa in the recent 100 years; through Canadian involvement in development in Burundi, Eritrea, Kenya, Rwanda, Somalia, Tanzania and Uganda. Canadian impact has been studied through the transformation of these countries and their peoples through impacts on family, culture, religion, education, economics and politics, inter alia. Also investigated is the extent to which Canada has been impacted. The lessons learned have been used to propose a possible shape for future Canadian engagement in development in Africa.
\end{abstract}

\section{Objectives}

The objectives of this paper are: to assess Canada's impact in the diffusion of engineering, science and technology in some selected countries in Africa in the recent 100 years; to investigate the extent to which Canada has been impacted by this diffusion; to point out lessons learned and to propose a possible shape of future Canadian policy and engagement in Africa for the next 100 years.

\section{Literature Review}

Diffusion of engineering, science and technology is the process through which they spread from source countries to others. Technological nativism is the tendency to believe that progress is to a large extent the result of a country's own people. Although indigenous skills and achievements are essential to technological advances, it is recognized that no nation is insular to the influences of other countries. Indeed, continued technological advances require infusion of new knowledge from elsewhere coupled with the ability to utilize it and a willingness to accept change.

Through adaptation and adoption diffusion could result in the emergence of new technologies. Moreover, the assumption that the use of technologies developed in advanced countries are essential to the economic and technological development of underdeveloped countries; can be challenged. However, to a large extent, foreign technologies can be a sound basis for indigenous development.

It has been observed that poor countries often lack human skills to effectively make use of advanced technologies. It is also recognized that these poor countries have large growing populations that require employment, hence use of Western technologies which tend to be capital intensive and intended to save labor may not be in the best interest of poorer nations. Hence, the contention: that technologies of the West may well distort the course of a country's development and leave it in a worse situation than when it started to embrace the technology.

There seems then to be need for appropriate technologies which in itself is not an easy thing to implement. Moreover, powerful groups in the poorer nations tend to influence what technology is transferred and only about $1 \%$ of international research and development funding is spent in the poor countries of the globe [1]. Diffusion occurs through peaceful trade, espionage, emigration, and war [2].

\section{Methodology}

The major Canadian impact in engineering, science and technology diffusion is assessed through Canadian involvement in development in Burundi, Eritrea, Kenya, Rwanda, Somalia, Tanzania, and Uganda. The main questions asked are: What is Canada's impact in the transformation of these countries and their peoples relative to impact on family, culture and religion, education, economics and politics? How has Canada been impacted by this diffusion? What lessons have been learnt? How should future Canadian involvement be shaped in the development of these countries for the next 100 years?

Data has been collected from Canadian International Development Agency (CIDA) projects and other sources including personal experiences of persons involved in the diffusion process. 


\section{Results and findings}

\subsection{Development Assistance in Burundi}

CIDA does not maintain a significant assistance program in Burundi and there are no long term projects planned in this country.

In 2003-2004, Canadian official development assistance to Burundi totaled $\$ 8.43$ million-nearly two-thirds of the total amount was humanitarian aid for famine relief, internally displaced persons and refugees.

Burundi also benefits from several regional projects that contribute to peace and stability. These include Canadian support to the International Conference for the Great Lakes Region; and the MultiCountry Demobilization and Reintegration Program (MDRP) that supports the return of ex-combatants to civilian life; and civil society activities in Rwanda, the Democratic Republic of Congo and Burundi that address human rights, citizen participation, the free flow of non-partisan information and conflict resolution.

Burundi, like all other countries and territories eligible for Canadian development assistance, can benefit from various programs. Examples of such programs are: geographic and multilateral programs including: the Pan-Africa Program, the La Francophonie Program, the Canada Fund for Africa, and the Humanitarian Assistance Program; and other programs that allow institutions, associations, Canadian and international non-governmental organizations and, private sector enterprises to receive funding from CIDA to execute projects worldwide; and the Canada Fund for Local Initiatives managed by the Canadian High Commission in Kenya.

Some development issues affect not only specific countries in Africa such as Burundi, but also entire regions. To meet such challenges effectively, CIDA's Pan-Africa Program offers direct support to pan-African organizations that wish to strengthen their organizational structures and skills.

CIDA funds Canada's contribution to $\mathrm{La}$ Francophonie, an international cultural and linguistic community of more than 170 million people who use French in their daily lives. The La Francophonie program has two priorities: strengthen democracy and the rule of law in La Francophonie and promote linguistic and cultural diversity [3].

\subsection{Development Assistance in Eritrea}

CIDA does not maintain a significant assistance program in Eritrea and there are no long term projects. Example of CIDA project in Eritrea is Food Security and Disaster Mitigation: in 2004-2005, Canadian official development assistance to Eritrea totaled \$9.06 million.Canada provides food aid and emergency assistance to Eritrea through multilateral institutions or international non-governmental organizations. Support in the form of emergency assistance focuses on health, nutrition, repatriation and emergency water supplies [3].

\subsection{Development Assistance in Kenya}

\subsubsection{Canadian Missionaries and Expatriates in Kenya}

Arthur Asa Grandville Carscallen (1879-1964) is an example of a Canadian missionary, administrator, and linguist who arrived in Kenya in late 1906 and opened up the work of the Seventh-day Adventists in Kenya, East Africa; with Peter Nyambo, an African teacher from Nyasaland (now Malawi) who had been schooling in England. In the 13 years of his pioneering work as Superintendent of the British East African Mission the following are the notable achievements in the diffusion process: established a string of mission stations along the eastern shore of Lake Victoria; in 1913 returning from furlough brought back a small platen press and a few pounds of type (Figure 1) and set up a small printing plant at Gendia to publish books, papers and a small monthly journal (Jaole Luo i.e. "The Luo Messenger"), Africans were taught to set type and the press still exists today; he mastered the Luo language and was the first to reduce it to writing, produced the grammar textbook that was widely used for many years, authored the Kavirondo Dictionary (Akawaio English dictionary) spent more than two years translating portions of the New Testament into the Luo language published by the British and Foreign Bible Society; he held the workers together during World War I when many of the mission stations were looted and damaged; founded the Kamagambo Training School in 1912. The tract of land given in 1913 to Carscallen was covered with bush and trees. It was no man's land between the Kisii and Luo tribes, and had been used by them as a battleground. The government believed and hoped that by giving it to the missionaries, peace would be preserved between the tribes. In 1922 a boarding school for girls was started. The girls were so timid that they had to be induced by promises of clothing. In 1928 a teacher training course was started, which the government recognized. In 1933 a boarding school for boys was opened [4].

Another notable Canadian missionary is E.A. Beavon who was Mission Director of the Seventh-day Adventist Church in Gusiiland, Kenya in 1922-28. He is reputed to have brought the bicycle as a means of transportation which was and is still used extensively today (Figure 2) [5].

Today, Adventists number approximately 2 million (nearly $6 \%$ of the Kenyan population). They are some of the most progressive, educated, etc. 


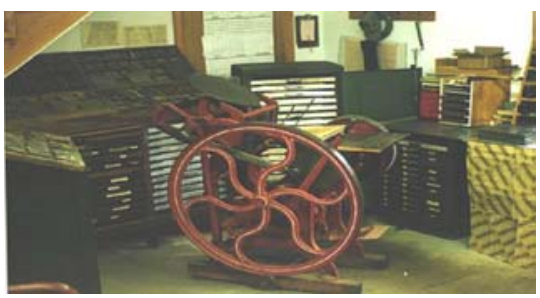

Figure 1. Typical 1897 Pedal Power Hand Set Letter Press

Source: www.wa6otp.com/challengegorden.htm

Since the early 1960s Canada has assisted Kenya in particular and the Eastern Africa region in manpower training of science teachers, college and university professors in chemistry, economics, engineering, geography and environmental studies, mathematics, surveying etc. through universities such as McGill, Toronto, Manitoba, Calgary.

Canadian teachers and professors have taught in schools, colleges and universities in Kenya and the region; providing much needed technical manpower including heading some of the institutions, academic departments and work supervision. For example, when KTTC was started in the late 1970s all faculty were initially Canadian; the first Principal (1980-85) of the first chartered private university (the University of Eastern Africa, Baraton) in Kenya was a Canadian, the very successful agricultural program and the farm were started by a Canadian professor who had worked in Tanzania in 1975-78. In all cases technology diffusion was experienced. Canada was also involved in wheat farming improvement in Kenya and Tanzania where other foreign experts had failed.

\subsubsection{Kenya Technical Teachers College (KTTC)}

KTTC was established with the primary objective of training technically skilled personnel to not only teach in the technical training institutions but also for employment in all sectors of the economy. With the mushrooming of Harambee Institutes of Technology; introduction of Technical Training Institutes, opening of private and other government ministries' training institutions (transport and water) and the expansion of the four national polytechnics (Kenya, Mombasa, Eldoret and Kisumu), the demand for technical teachers increased. As a result the Kenya government approached and held discussions with the government of Canada to build KTTC through CIDA between 1973 and 1978. KTTC is a unique professional institution offering courses that lead to the award of certificates, diplomas and higher diplomas in various disciplines. These diplomas place the students who wish to pursue further education at university at great advantage, since credits are offered for courses successfully completed [6].

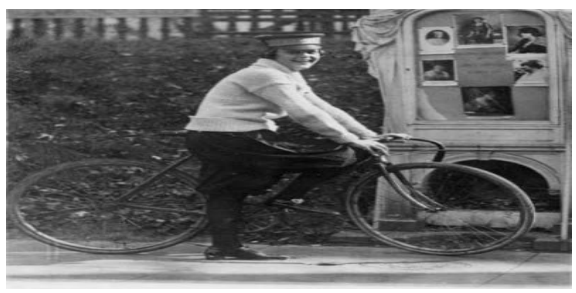

Figure 2. Typical 1922 Bicycle

Source:

http://womenshistory.about.com/library/pic/bl_p_1922_bicycle.htm

Figure 3 shows the total number of KTTC students for the period 1979-2005 in Technical (TECH), Industrial (IND), Mechanical Engineering (ME), Electrical and Electronic (EE), Building and Civil Engineering with options in Quantity Surveying/ Architecture, Water Engineering, and Building Economics (BCE); and Computer Science and Computer Maintenance (CS) diploma programs.



Figure 3. Total KTTC Students (1979-2005) in Engineering, Technical and Industrial Programs

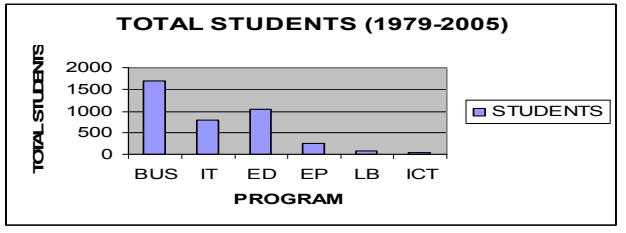

Figure 4. Total KTTC Students (1979-2005) in Business and related Programs

Figure 4 shows the total number of KTTC students for the period 1979-2005 in Business Administration, Cooperative Management, Accounting (BUS); Information Technology (IT), Technical Teachers Education and Educational Management (ED), Entrepreneurship Development Program (EP), Library and Information Studies (LB), and Information and Computer Technology (ICT) diploma programs including Secretarial studies.

Figure 5 shows the growth of KTTC total students in all courses for the period 1979 to 2005 . A steady upward trend can be seen. 


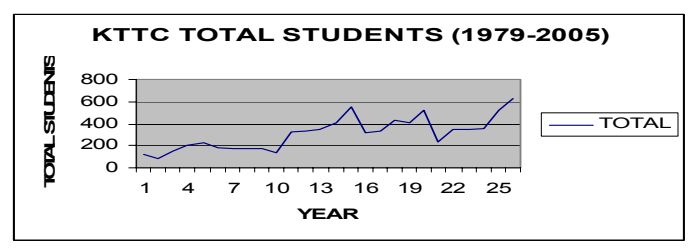

Figure 5. Growth in KTTC Total Students (19792005)

\subsubsection{CIDA Projects in Kenya}

In Kenya, CIDA is committed to enhancing the country's ability to set its own development agenda and to increasing its capacity to manage its development resources. CIDA's bilateral program with Kenya supports the priorities identified in Kenya's Poverty Reduction Strategy Paper (PRSP): gender equity, fight against HIV/AIDS, education, governance and democratic development priorities are also central to the New Partnership for Africa's Development (NePAD) and the UN Millennium Development Goals.

(1) The Gender Equity Support Project (GESP) is CIDA's gender fund in Kenya. The GESP program focuses on women's human rights, legal and economic empowerment, women in leadership and decisionmaking and gender equality. GESP was launched in 1996 and continues to support large and small initiatives led by non-governmental organizations (NGOs), specific government bodies and various coalitions working strategically on gender equality issues. Strategic partnerships, local capacity building and financial assistance combine to promote women's empowerment and their participation as equal and effective agents of change in the sustainable development of their society.

(2) The Kenya School Improvement Project aims at improving access to and participation in, basic education as well as improving the quality of education offered in Kenya. The Kenyan government believes that basic education is a priority and has declared all primary education in the country should be offered free to all. As a core value and priority of CIDA's work, Canada is supporting this vital Kenyan initiative, focusing on developing appropriate strategies to ensure that girls as well as boys have equitable access to quality education. This project is being implemented by the Aga Khan Foundation and the Kenyan Ministry of Education, Science and Technology in the Kwale District (Kenya).

(3) The Democratic Governance Fund supports activities and initiatives of the Government of Kenya and its agents by promoting democratic values and respect for human rights and aims to enhance Kenya's representative government and civil society organizations.
(4) The Strengthening STD/HIV Control in Kenya Project aims to reduce the incidence of sexually transmitted diseases (STDs), including AIDS, in Kenya. An effective community-based approach to controlling STDs/AIDS has been established by developing and disseminating low-cost, low-technology health procedures and by training health workers. This project has contributed to the decline of STDs and HIV prevalence. This initiative is being implemented jointly by the University of Manitoba and the University of Nairobi.

(5) The Support to Free Primary Education in Kenya Project supports Kenya in reaching its education for all targets by aiming to achieve quality primary education for all Kenyan school-aged children by 2005. Canada's contribution consists of two components: a cash contribution to a pooled fund, to be managed by the United Kingdom's Department for International Development (DFID), for the provision of instructional materials; and a locally-administered technical assistance fund in support of the government's Education Sector Strategic Plan (ESSP).

Additionally, a good number of Canadian institutions and NGOs, in partnership with local organizations, provide support in areas of education and health [3].

\section{(6) Trade and Investment}

The mandate of the Commercial Section, of the Canadian High Commission in Kenya, is to promote and protect Canada's economic interests in Burundi (B), Eritrea (E), Kenya (K), Rwanda (R), Somalia (S) and Uganda (U). It supports the efforts of Canadian companies that have chosen one of these countries as a market for their products, services, technologies and investment. It also provides assistance to clients from those countries by matching their needs with the appropriate sources of Canadian products and services [7].

\subsection{Development Assistance in Rwanda}

Since the late 1950s, towards the end of the Belgian Protectorate, Rwanda has experienced a series of civil and ethnic conflicts, culminating in the genocide of 1994, in which more than 800,000 Rwandans were killed and half the population was displaced. National reconciliation and decentralizing power to local authorities have been key to government efforts to rebuild the country's physical and social capital.

In order to take charge of its own development, in 2002, Rwanda introduced its own PRSP. Within the PRSP, the Government of Rwanda set the goal of reducing the proportion of Rwanda's population living in poverty by half by 2015 . To this end, the PRSP concentrates investments in six priority areas: rural development and agricultural transformation, human development, economic 
infrastructure, good governance, private sector development, institutional capacity building.

Although it remains a very poor country, Rwanda has demonstrated an increased awareness and concern for its role on an international level. It has started to rebuild its often volatile relationships with the Democratic Republic of the Congo and Uganda, and is a major player in the International Conference on the Region of the Great Lakes. In addition, Rwanda has chosen to participate in the New Partnership for Africa's Development (NEPAD) as one of the first countries to submit to a peer review of its governance.

Canada has been present in Rwanda since 1963 actively developing programs to improve the quality of life of the country's poor, as well as building infrastructure, justice, higher education and governance systems. Since the civil war and genocide of 1994, CIDA has contributed a total of $\$ 240$ million in aid to Rwanda, including \$21.11 million in 2004-2005.

More recently, Rwanda has been recognized as one of the 25 development partner countries in which CIDA will concentrate the major part of its bilateral (country to country) assistance.

In May 2005, CIDA approved a new Country Development Programming Framework (2005-2011) for Rwanda. Working within the priorities established by the Government of Rwanda, Canada focuses its assistance in the areas of rural development or private sector development and local governance. Major program objectives include: diversifying the rural economy; increasing agricultural production and productivity; reducing peasant farmers' vulnerability to the uncertainties of climate and market; and bolstering the capacities of decentralized local authorities and of rural associations to conceive and implement concrete local development plans. Environmental protection, gender equality, and supporting the struggle against HIV/AIDS are crosscutting themes in all programming.

The focus on these program priorities in earlier projects has led to notable results. For instance, as a result of past community development projects with returned refugees, thousands of Rwandan families are better housed; grow and sell a wider variety of crops; and have better access to water, education and, health services.

In Figure 6 a man builds a house as part of the CIDA-funded Murambi Integrated Community Development Program, which provides housing for thousands of returning refugees and internally displaced Rwandans. Before the 2001 district elections and 2003 constitutional referendum, CIDA supported voter education. Women now make up $25 \%$ of district councils and $48 \%$ of the national parliament.

Canada provides humanitarian assistance and food aid to Somalia through multilateral organizations. In the year 2002/03, Canada provided close to $\$ 1.5$ Million in support of this assistance.

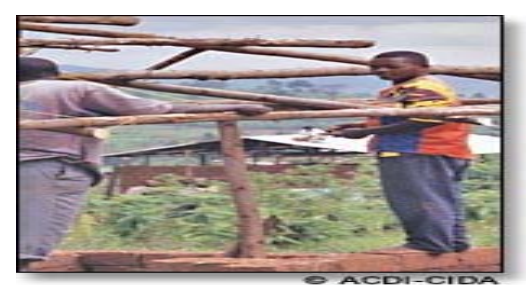

Figure 6. House building in Rwanda

\subsection{Development Assistance in Somalia}

Canada also provides support in the area of peace building; supporting local and international organizations involved in areas including small arms, mine action, human rights and war-affected children.

\subsection{Development Assistance in Tanzania}

Although one of the world's poorest countries, Tanzania has a stable, multi-party democracy with one of the continent's better governance records. It is one of Africa's most politically and socially stable countries. In fact, it plays a prominent role in conflict resolution in the East African region.

Since 1995, the Government of Tanzania has pursued a comprehensive economic reform and poverty reduction agenda that has resulted in macro-economic stability, steady economic growth, and progress toward the Millennium Development Goals. In 2004, Tanzania signed on to NePAD, which includes submitting to a peer review of its governance.

Tanzania is a leader in taking control of its own development and fostering coordination among donors. Tanzania's second poverty reduction strategy, the National Strategy for Growth and Reduction of Poverty, concentrates efforts in three areas: growth and reduction of income poverty; improvement of quality of life and social well-being; and governance and accountability.

Although the incidence of poverty remains high, Tanzania has demonstrated its strong commitment to translating recent macro-economic gains into real improvements in living standards at the grass-roots level. It is a country with great potential. With sustained commitments to its national strategy, Tanzania's prospects of realizing that potential are improving.

Canada and Tanzania have a long history of development cooperation. Since the late 1960s, Canada has contributed over $\$ 1$ billion to a broad range of initiatives in sectors such as education, transportation, agriculture, and health.

Tanzania is one of the 25 development partner countries in which CIDA will concentrate the major part of its bilateral assistance.

CIDA currently provides support to Tanzania's poverty reduction efforts in the following 
four areas: education; health and HIV/AIDS; governance; and private sector development. Gender equality, environmental sustainability, and HIV/AIDS are crosscutting themes in all CIDA programming.

Canada is increasingly engaged in innovative ways to make aid more effective in Tanzania. In line with its policy statement, CIDA has been phasing out traditional projects managed by Canadian executing agencies and moving to fewer, larger, and more strategic programs that are country-led and supported by several donors.

In addition, CIDA and other donors fully support the priorities set out in the Government of Tanzania's second poverty reduction strategy and is working with them to establish a Joint Assistance Strategy, which aims to streamline donor support. Tanzania is a model for international efforts to harmonize donor assistance.

Canada's support to Tanzania has contributed to a number of important results in recent years, such as: increased agricultural yields through use of livestock manure and fertilizer; increases in primary school enrolment rates from below 60 percent in the late 1990s to 95 percent in 2005. More than 7.5 million children are now enrolled in primary school, up from 4.4 million in 2000; the creation of Tanzania's first permanent national voters' register in 2005 and the registration of $8,500,000$ voters by the Tanzania National Electoral Commission; and through the purchase of anti-retroviral medication, by $2005,8,000$ people living with HIV/AIDS received free treatment $[8]$.

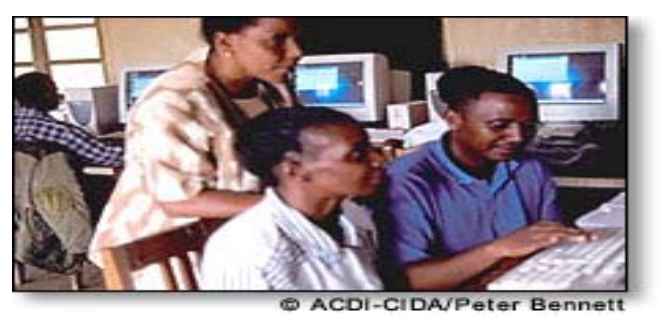

Figure 7. Tanzanian teachers sharpening their computer skills

CIDA-supported projects provide teachers in Tanzania with additional teaching resources and help them sharpen their skills in areas such as computer training (Figure 7).

\subsection{Development Assistance in Uganda}

Canada began providing development assistance in Uganda in 1965 and has been involved in projects focusing on the following development themes/priorities: basic human needs, women in development, infrastructure services, human rights, democracy and good governance, private sector, protection of the environment.

Currently, CIDA's development focus is exclusively centered on the field of basic education. CIDA provides support through Uganda's Education Strategic Investment Plan (ESIP), the national education reform plan, focused on the needs of disadvantaged children. Working closely with donors, such as Canada, Uganda's ESIP integrates all educational activities and implements its own programs and activities.

Sector-wide approaches (SWAPS), such as ESIP, involve coordinated efforts to set out strategic approaches in a particular sector (such as health or education). This may involve implementing projects that support sectoral plans or contributing aid funds to a common pot that the developing country would then use to implement its sectoral plan. These strategies place a premium on local ownership and donor coordinator and embody a comprehensive approach to development. They also reflect a strong emphasis on strengthening government capacity in developing countries, through the provision of technical assistance and the establishment of policy environments which enable social and economic progress - critical underpinnings of sustained development aid effectiveness.

Canada contributes to the Central Africa and Great Lakes Program administered by the World Bank for a MDRP for ex-combatants in the greater Great Lakes area including Uganda.

CIDA's Peace-building Fund activities focus on peace-building initiatives in Northern Uganda as well as on the reintegration of former child soldiers. Support is also being provided to integrate conflict resolution skills and mine risk education in school curricula.

Additionally, a good number of Canadian institutions and NGOs, in partnership with local organizations, provide support to health-related projects, as supported by CIDA's Canadian Partnership Branch, and humanitarian aid targeting young children [3].

\subsection{Projects by Other Agencies}

\subsubsection{Girl Child Network (GCN)}

Created by CARE Canada as part of Girl Child Program and funded by a $\$ 322,000$ grant from the Government of Canada

In Kenya the GCN has had a dramatic impact. For example, the network was instrumental in the enactment of the Government of Kenya's Children's Act, aimed at protecting the rights of children especially girls. In particular 6 members of the GCN accompanied 12 Kenyan children to the United Nations 
General Assembly Special Session on Children in New York, ensuring Kenyan voices are heard in the worldwide fight for children's rights.

\subsubsection{CIDA Children' Rights and Protection Unit}

Established in 1960 and supports sustainable development in developing countries, in order to reduce poverty and to contribute to a more secure, equitable and prosperous world. The social development work focuses on health, education, HIV/AIDS for ages 0-18 [9].

\subsubsection{Canadian Bahai International Development Agency}

Incorporated 1981 and dedicated to international social and economic development. Past initiatives include primary healthcare projects in Kenya and Uganda [10].

\subsubsection{University of Alberta International}

Completed Africa Management Project (AMP) through CIDA funding, worked directly with the senior levels of Management Development Institute (MDI) to negotiate strategic reforms of management educational institutions in Kenya. Women in management component of AMP supported management and program development to improve the situation of women managers in Kenya and Tanzania.

In Kenya the following projects have been undertaken: (1) The valuation of the environmental services provided by agroforestry systems, whose purpose was to develop, apply and disseminate methods for economic valuation of the goods and services generated by agroforestry and alternative land use systems that are relevant to the needs of policy makers across ICRAF's mandate area. (2) Development of Human resources in agroforestry intended to improve the qualification of teaching staff and students and to enhance human resource development in agroforestry. (3) Home Economics Faculty Upgrading at Kenyatta University.

In Tanzania the Medical Education Enhancement Program consisted of a teaching enhancement and staff development program in collaboration with the Faculty of Medicine, including program delivery through distance education.

In Uganda Measuring the Burden of Informal Care Givers of AIDS Patients in Kabarole District provided baseline data about informal caregiver burden through the collection of information from the caregiver's perspective. The project also described how a developed country can learn from a developing country through the research process and from the research results. Also, describing how lessons learned can be applied in the developed country to disadvantaged populations [11].

\subsubsection{Adventist Development and Relief Agency (ADRA) Canada}

ADRA Canada is funding the Gatsibo Civil Society Empowerment Project and together with the Rural Support Project/Rwanda 11,000 rice farmers have been reached.

\subsection{Some Facts and Figures about Canada and the Selected African Countries}

The selected African countries' combined population of approximately 132 million is 4 times as large as Canada's population. Canada's population is a little over 30 million, just behind Kenyas's and just ahead of Uganda's (Figure 8).

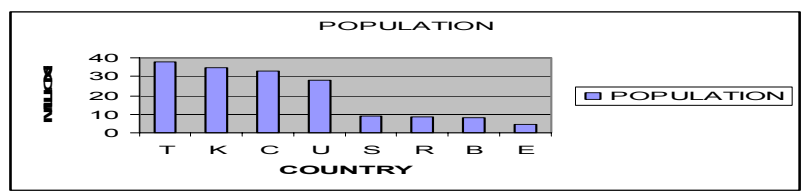

Figure 8. Population

In terms of GDP (Figures 9, 10) Canada's GDP of about 1000 billion US $\$$ is nearly 22 times that of Uganda (the highest GDP of the selected African countries) and nearly 200 times that of Burundi (the lowest GDP of the lot).

Table 1 shows the agricultural production in the countries studied. Common to all are wheat, tobacco, fruits, vegetables, dairy and fish production. Canada does not produce the rest of the products in the table on the basis of the information used.



Figure 9. GDP (billion US\$) of Canada and the Selected African Countries



Figure 10. GDP of the Selected African Countries

Table 2 shows the major trading partners of the countries studied. None of the selected African 
countries are major trading partners with Canada. However, Japan, U.S.A., U.K. and China that are Canada's major trading partners are also major trading partners of the selected African countries.

Table 3 shows the religious affiliations in the countries studied, indicating the presence of Islam in every country with Somalia $100 \%$ Islam. It should also be noted that Zanzibar (the island nation of Tanzania) is 99\% Islam. Only in Canada and Rwanda are population segments without religious affiliation. Over the last 100 years the African countries' populations have been transformed from indigenous religions to Christianity and Islam.

Figure 11 shows the current literacy rates. Over the last 100 years the literacy rate for the selected African countries has grown from near $0 \%$ to nearly 40 $80 \%$.

\section{Discussion}

What is Canada's impact in the transformation of these countries and their peoples relative to family, culture and religion, education, economics, and politics? In Burundi, Eritrea, and Somalia Canada, through CIDA, does not maintain significant assistance programs. In 2000-2007, this assistance has been in the form of humanitarian aid for famine relief/enhancing food security, disaster mitigation through emergency assistance in health, nutrition, water supply and repatriation of displaced persons and refugees; peace building; strengthening democracy and the rule of law; dealing with small arms, mine action, human rights and war-affected children; and promoting linguistic and cultural diversity.

In Kenya, Rwanda, Tanzania and Uganda through CIDA and other Canadian agencies Canada has maintained significant assistance programs over the last 100 years. Diffusion has occurred through transfer of religion (1906), transfer of printing (1913), transfer of literacy (1913-1933), transfer of education and technical programs (1960-1999) and 2000 to present: gender equity and women empowerment, school improvement with increases in primary school enrolment rates, democratization, improved quality of life of the poor, better housing, reduction in incidence of STDs and HIV/AIDS, peace building, environmental protection and sustainability, and improved farming

How have Canada and Canadians been impacted by this diffusion? Firstly, the Canadians involved, in projects in these countries, have been impacted directly. They have so strong a connection that even their children find it easy to return to Africa on different projects. They found it easy to adapt to Africa. They particularly enjoyed the flora and fauna of these countries. In these African countries the bird population easily numbers twice as much as in Canada. Both good and bad experiences are memorable. In some areas they had to cope with poisonous snakes, scorpions, weevils, termites, malaria causing mosquitoes etc. For the agriculturalist and biologists the plant variety, especially the fruits, was something they enjoyed. The cultural exchange that takes place helps the individuals to be more in tune with people from different cultures. They no longer see themselves as Canadians but as citizens of the world; more so due to the fact that they find people with similar faith and church. The cultural barriers break down.

Expatriate mothers and housewives acquire experience in coping without running water, electricity, gas and having to fetch water from the springs, or catching rain water, cooking with firewood and charcoal or limited supplies of gas or some alternative fuels. Where there is house-help, this helps considerably. Expatriate children learn to help with these chores where there is no house-help. These chores are very time consuming. Despite these seeming difficulties some spouses were able to enroll for degree work and graduate while their spouses were serving out there. Thus, not only do they impact the people there through teaching English (and other foreign languages) in formal settings but impart language skills through everyday conversation and church involvement. They may also pick the African languages.

Expatriate children have to be home schooled if no overseas school exists or where one is not established for expatriate families. Often the children have to be sent to boarding schools in neighboring countries or overseas. Some kids resented this as it separated them from family and lost the comforts of home, parental care and guidance. When the children reached college age some expatriates were forced to return home so that they could be near their children.

Canadian expatriates sense isolation when living out there but confess that their work is not as stressful as back home in the West. More could be done by the Canadian High Commissions/Embassies and host countries to reduce the isolation.

Nearly everything in the West is disposable. Living overseas changes one's mind to the extent that one builds a culture of reusing things that would otherwise be disposed of. Other habits that have been acquired include bulk purchasing of commodities.

Canada has also been impacted as a country through immigration from the selected countries: during Idi Amin's regime in Uganda part of the mass exodus of Asians ended up in Canada impacting Canada through their entrepreneurial skills. Some have immigrated to seek refuge, education or simply better opportunities.

Canadians are cognizant of the fact that industrialized and developing countries are interdependent, and that Canadian interests and values are served by promoting global cooperation and equality. Canada continues to prosper even as it gives 
and employment opportunities are created for Canadians through the diffusion process.

What lessons have been learned?

Expatriates going overseas tend to have a rather narrow world view. As a result they do not treat people properly and graciously. Upon return they find that they are more mature and contrite. This could be resolved by involving students in internships before graduating.

Expatriates are able to evaluate their country's foreign policy more critically and their views should be used to shape future foreign policies. Mission institutes that are used for orientation and debriefing should provide lessons learned as input towards foreign policy revisions.

How should future Canadian involvement be shaped in the development of these countries for the next 100 years? Using a compound growth rate formula $\mathrm{G}_{\mathrm{F}}=\mathrm{G}_{\mathrm{C}}(1+\mathrm{r})^{n}$ where $\mathrm{G}_{\mathrm{C}}$ is the current GDP and $\mathrm{G}_{\mathrm{F}}$ is the future GDP. Calculations indicate that for Uganda to reach Canada's current GDP, assuming it grows at its current real growth rate of $9 \%$ it will take nearly 37 years. Alternatively, if Uganda were to take 20 years to attain Canada's current GDP, it will have to grow at an annual rate of $17 \%$ (nearly twice its current real growth). Similar calculations for Burundi indicate that it needs nearly 125 years to attain Canada's current GDP if it continues to grow at its current rate of nearly 4.5\%. Alternatively for Burundi to reach Canada's current GDP in the next 20 years, it will need to grow at $32 \%$ per annum ( 7 times its current growth rate). The rest of the countries lie in between Uganda and Burundi. Clearly it will take a miracle for these countries to transform! Little wonder the term "Millennium Development Goals" has been used.

Canada's development assistance to some of these countries is significant. However, more needs to be done by way of equitable trade with these countries. Past successes should be duplicated where applicable, and failures not repeated. It is hard to imagine that a genocide would occur in Rwanda (a Christian nation) whilst Canada, the Eastern Africa region and the rest of the world watched! Somali has been without a government for decades! Insecurity and corruption still dog some of the countries. Clearly the economies of these African countries require to be accelerated through radical transformation (industrial revolution) in which there will be a discontinuity with the past. These countries are deficient of the infrastructure required to radically accelerate their economies. Canada and other donors together with the selected African countries hold the key to the required diffusion. There seems to be a semi-permeable membrane hampering the transformation. This semi-permeable membrane is made up of a labyrinth of inertia, corruption, insecurity, poor leadership, illiteracy, disease, lack of capital, inter alia. Once these are sufficiently addressed viable strategies can be formulated. Canada and other countries should be the catalysts for the radical transformation of these countries. There should be teaching and mentoring in innovation, entrepreneurship, infusion of knowledge in common areas of industry, employment creation etc.

Table 1. Agriculture

\begin{tabular}{|c|c|c|c|c|c|c|c|c|}
\hline \multicolumn{9}{|c|}{ COUNTRY } \\
\hline & $\mathbf{B}$ & $\mathbf{C}$ & $\mathbf{E}$ & $\mathbf{K}$ & $\mathbf{R}$ & $\mathbf{S}$ & $\mathbf{T}$ & $\mathbf{U}$ \\
\hline \multicolumn{9}{|l|}{ AGRICULTURE } \\
\hline Coffee & $\mathrm{X}$ & & $\mathrm{X}$ & $\mathrm{X}$ & $\mathrm{X}$ & & $\mathrm{X}$ & $\mathrm{X}$ \\
\hline Cotton & $\mathrm{X}$ & & $\mathrm{X}$ & & & & $\mathrm{X}$ & $\mathrm{X}$ \\
\hline Tea & $X$ & & & X & $X$ & & X & X \\
\hline Corn & $\mathrm{X}$ & & $X$ & $\mathrm{X}$ & & $\mathrm{X}$ & $\mathrm{X}$ & $\mathrm{X}$ \\
\hline Sorghum & $X$ & & $\mathrm{X}$ & & & $\mathrm{X}$ & & \\
\hline Sweet Potatoes & $\mathrm{X}$ & & & & & & & $\mathrm{X}$ \\
\hline Bananas & $X$ & & & & $\mathrm{X}$ & $\mathrm{X}$ & $\mathrm{X}$ & $\mathrm{X}$ \\
\hline Manioc (Tapioca) & $X$ & & & & & & X & X \\
\hline Beef & $\mathrm{X}$ & & & $\mathrm{X}$ & & & & $\mathrm{X}$ \\
\hline Milk & $X$ & & & & & & & \\
\hline Hides & $X$ & & & & & & & \\
\hline Wheat & & $\mathrm{X}$ & & $\mathrm{X}$ & & & $\mathrm{X}$ & \\
\hline Barley* & & $\mathrm{X}$ & & & & & & \\
\hline Oilseed* & & $X$ & & & & & & \\
\hline Tobacco* & & $\mathrm{X}$ & $\mathrm{X}$ & & & & $\mathrm{X}$ & \\
\hline Fruits* & & $X$ & & $\mathrm{X}$ & & & $\mathrm{X}$ & \\
\hline Vegetables* & & $\mathrm{X}$ & $\mathrm{X}$ & $\mathrm{X}$ & & & $\mathrm{X}$ & \\
\hline Dairy Products* & & $\mathrm{X}$ & & $\mathrm{X}$ & & & & \\
\hline Forest Products* & & $X$ & & & & & & \\
\hline Fish* & & $\mathrm{X}$ & $\mathrm{X}$ & & & $\mathrm{X}$ & & \\
\hline Sisal & & & $\mathrm{X}$ & & & & $\mathrm{X}$ & \\
\hline Livestock & & & $\mathrm{X}$ & & & & & \\
\hline Goats/Goat meat & & & $\mathrm{X}$ & & & $\mathrm{X}$ & $\mathrm{X}$ & $\mathrm{X}$ \\
\hline Sugarcane & & & & $X$ & & $\mathrm{X}$ & & \\
\hline Pork & & & & $\mathrm{X}$ & & & & \\
\hline Poultry & & & & $\mathrm{X}$ & & & & $\mathrm{X}$ \\
\hline Eggs & & & & $\mathrm{X}$ & & & & \\
\hline Pyrethrum & & & & & $X$ & & $\mathrm{X}$ & \\
\hline Beans & & & & & $X$ & $\mathrm{X}$ & & \\
\hline Coconuts & & & & & & $\mathrm{X}$ & & \\
\hline Rice & & & & & & $X$ & & \\
\hline Mangoes & & & & & & $\mathrm{X}$ & & \\
\hline Cattle & & & & & & $\mathrm{X}$ & $\mathrm{X}$ & \\
\hline Sheep & & & & & & $X$ & $\mathrm{X}$ & \\
\hline Cloves & & & & & & & $\mathrm{X}$ & \\
\hline Millet & & & & & & & & $\mathrm{X}$ \\
\hline Pulses & & & & & & & & $\mathrm{X}$ \\
\hline Cut flowers & & & & & & & & $\mathrm{X}$ \\
\hline
\end{tabular}


Table 2. Major Trading Partners

\begin{tabular}{|c|c|c|c|c|c|c|c|c|}
\hline \multicolumn{9}{|c|}{ MAJOR TRADING PARTNERS } \\
\hline & B & $\mathbf{C}$ & $\mathbf{E}$ & $\mathbf{K}$ & $\mathbf{R}$ & $\mathbf{S}$ & $\mathbf{T}$ & $\mathbf{U}$ \\
\hline B & & & & $X$ & $\mathrm{X}$ & & $\mathrm{X}$ & $\mathrm{X}$ \\
\hline $\mathrm{C}$ & & & & & & & & \\
\hline $\mathbf{E}$ & & & & & & & & \\
\hline $\mathbf{K}$ & & & & & $\mathrm{X}$ & $\mathrm{X}$ & $\mathrm{X}$ & $\mathrm{X}$ \\
\hline $\mathbf{R}$ & & & & & & & & $\mathrm{X}$ \\
\hline $\mathbf{S}$ & & & & & & & & \\
\hline $\mathbf{T}$ & & & & $\mathrm{X}$ & & & & \\
\hline $\mathbf{U}$ & & & & $\mathrm{X}$ & $\mathrm{X}$ & & & \\
\hline Belgium & $\mathrm{X}$ & & & & $\mathrm{X}$ & & & $\mathrm{X}$ \\
\hline France & $\mathrm{X}$ & & & & $\mathrm{X}$ & & & $\mathrm{X}$ \\
\hline Germany & $\mathrm{X}$ & & $\mathrm{X}$ & & $\mathrm{X}$ & & & $\mathrm{X}$ \\
\hline Italy & $\mathrm{X}$ & & $\mathrm{X}$ & & & & & \\
\hline Japan & $\mathrm{X}$ & $\mathrm{X}$ & $\mathrm{X}$ & $\mathrm{X}$ & & & $\mathrm{X}$ & $\mathrm{X}$ \\
\hline Pakistan & $\mathrm{X}$ & 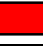 & & & & & & \\
\hline U.S.A. & $\mathrm{X}$ & $\mathrm{X}$ & $\mathrm{X}$ & $\mathrm{X}$ & & & $\mathrm{X}$ & $\mathrm{X}$ \\
\hline UK & & $\mathrm{X}$ & & $\mathrm{X}$ & & & $\mathrm{X}$ & $\mathrm{X}$ \\
\hline China & & $X$ & $\mathrm{X}$ & & $\mathrm{X}$ & & $\mathrm{X}$ & $\mathrm{X}$ \\
\hline Mexico & & $X$ & & & & & & \\
\hline Malaysia & & & $X$ & & & & & \\
\hline Egypt & & & $\mathrm{X}$ & $\mathrm{X}$ & & & & \\
\hline India & & & $X$ & $X$ & & $\mathrm{X}$ & $\mathrm{X}$ & $\mathrm{X}$ \\
\hline Ireland & & & $X$ & & & & & \\
\hline Turkey & & & $\mathrm{X}$ & & & & & \\
\hline Netherlands & & & & $X$ & & & $\mathrm{X}$ & $\mathrm{X}$ \\
\hline Saudi Arabia & & & & $\mathrm{X}$ & & & & \\
\hline South Africa & & & & $X$ & & & $\mathrm{X}$ & $\mathrm{X}$ \\
\hline UEA & & & & $\mathrm{X}$ & & $\mathrm{X}$ & $\mathrm{X}$ & $\mathrm{X}$ \\
\hline Indonesia & & & & & $\mathrm{X}$ & & & \\
\hline Yemen & & & & & & $\mathrm{X}$ & & \\
\hline Oman & & & & & & $\mathrm{X}$ & & \\
\hline Djibouti & & & & & & $\mathrm{X}$ & & \\
\hline Brazil & & & & & & $\mathrm{X}$ & & \\
\hline Spain & & & & & & & $\mathrm{X}$ & \\
\hline
\end{tabular}

Table 3. Religion

\begin{tabular}{|l|c|c|c|c|c|c|c|c|}
\hline \multicolumn{9}{|c|}{ COUNTRY } \\
\hline $\begin{array}{c}\text { RELIGION } \\
(\%)\end{array}$ & $\mathrm{B}$ & $\mathrm{C}$ & $\mathrm{E}$ & $\mathrm{K}$ & $\mathrm{R}$ & $\mathrm{S} * * *$ & $\mathrm{~T}$ & $\mathrm{U}$ \\
\hline R Catholic & 62 & 43 & $*$ & 33 & 57 & & & 33 \\
\hline Protestant** & 5 & 23 & $*$ & 45 & 26 & & & 33 \\
\hline Christian & & 4 & $*$ & & & & 30 & \\
\hline Adventist & & & & & 11 & & & \\
\hline Islam & 10 & 2 & $*$ & 10 & 4.6 & 100 & 35 & 16 \\
\hline Indigenous & 23 & & & 10 & 0.1 & & 35 & 18 \\
\hline Others & & & & 2 & & & & \\
\hline None & & 16 & & & 1.7 & & & \\
\hline
\end{tabular}

Notes:

* Present but no figures are available

** United Church, Anglican, Baptist, Lutheran

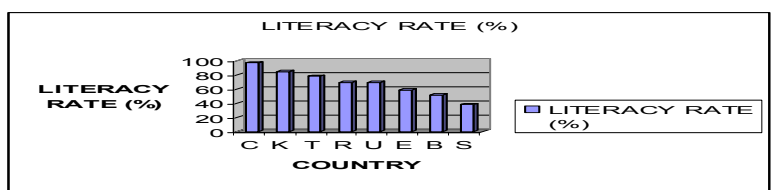

Figure 11. Literacy rate

\section{Conclusion}

It can be concluded that Canada and the selected African countries have been mutually impacted in the last 100 years through the diffusion of engineering, science and technology. However, the impact and diffusion has not been sufficient for the radical transformation of the selected African countries. In deed the African countries should not expect that donor funding and initiatives alone will cause the radical transformation they so desperately need.

\section{Recommendations}

This study should be continued in a quantitative and qualitative manner in order to develop viable strategies for the radical transformation of the selected African countries whose success should be emulated by other countries with similar conditions.

\section{Acknowledgements}

Agoki Omenge for information on missionaries in East Africa; and Judy Chittick for impact on Canadians are acknowledged. Time Almanac 2007 for data.

\section{References}

[1] Volti, Rudi. Society and Technological Change, $4^{\text {th }}$ Ed., Worth Publishers, New York. 2001. pp 69-78.

[2] Jared Diamond. Guns, Germs, and Steel, W.W. Norton \& Co., Inc. New York, 1999. p. 256

[3] www.dfait-maeci.gc.ca

[4] Don F. Neufeld (Editor), Seventh-day Adventist Encyclopedia, Revised Ed., Commentary Vol. 10, Review and Herald Publishing Association, Washington D.C., 1976, pp. 239, 731

[5] Ibid p. 731

[6] www.kttc.ac.ke

[7] www.dfait-maeci.gc.ca/nairobi/trade_ investment-en.asp

[8] www.acdi-cida.gc.ca/

CIDAWEB/acdicida.nsf/En/JUD-21712472NUX?OpenDocument

[9] www.crin.org/organisations/viewOrg.asp?ID=1482.

[10] www.ca.bahai.org/main.cfm?sid=99

[11] www.international.ualberta.ca/intlpartners Africa.php?id=255 